\title{
Multiple-layered structure of obelisk-shaped crystalline nano-ZnO prepared by sol-gel route
}

\author{
Saeideh Jurablu $^{1}$ - Majid Farahmandjou ${ }^{1} \cdot$ Tahereh Pormirjaafari Firoozabadi $^{1}$
}

Received: 31 January 2015/ Accepted: 29 July 2015/Published online: 21 August 2015

(c) The Author(s) 2015. This article is published with open access at Springerlink.com

\begin{abstract}
Zinc oxide nanopowders were synthesized by the simple sol-gel method from an ethanol solution of zinc nitrate hexahydrate. Structural and surface morphological investigations were carried out using X-ray diffraction (XRD), high-resolution transmission electron microscopy (HRTEM), scanning electron microscopy, Fourier transform infrared spectroscopy (FTIR) and ultraviolet-visible (UV-Vis) spectrophotometry analyses. XRD pattern showed that the zinc oxide nanoparticles exhibited hexagonal wurtzite structure. A multiple-layered structure of obelisk-shaped $\mathrm{ZnO}$ nanoparticles was achieved after calcinations. The average particle size of $\mathrm{ZnO}$ was around $20 \mathrm{~nm}$ as estimated by direct HRTEM observation. The size of sphere-like shaped $\mathrm{ZnO}$ nanoparticles was measured in the range of $20-80 \mathrm{~nm}$ and the size of pyramid-like shaped annealed samples was achieved in the range of 40-100 nm with less agglomeration. The energy dispersive spectroscopy spectrum showed peaks of zinc and oxygen. The sharp peaks in FTIR spectrum determined the $\mathrm{Zn}-\mathrm{O}$ stretching and absorbance peak of UV-Vis spectrum showed the wide bandgap energy of $3.35 \mathrm{eV}$.
\end{abstract}

Keywords $\mathrm{ZnO}$ nanoparticles · Obelisk-shaped · Synthesis $\cdot$ Sol-gel

Majid Farahmandjou

farahmandjou@iauvaramin.ac.ir

1 Department of Physics, Varamin Pishva Branch, Islamic Azad University, Varamin, Iran

\section{Introduction}

$\mathrm{ZnO}$ has received lot of attention as a nanostructured material because of its unique properties rendering it suitable for various applications. One-dimensional nanostructures exhibit interesting electronic and optical properties due to their low dimensionality leading to quantum confinement effects. The novel properties of nanoscale zinc oxide particles have found applications in a variety of applications such as luminescence [1-3], varistors [4, 5], solar cells [6], gas sensors [7, 8]. Many of the synthetic approaches such as sol-gel method [13], co-precipitation [12], hydrothermal method [14], microwave synthesis [911], and thermal evaporation method [15] have been used for the preparation of $\mathrm{ZnO}$ powders. Amongst the different methods of synthesis of $\mathrm{ZnO}$ nanostructures, the sol-gel method is attractive for its simplicity and environmentfriendly conditions. Sol-gel preparation of solid catalysts has been reported by many research groups [16-20]. Using this method, the crystal grain can develop completely and the particle size is uniform. The soft-chemistry routes especially sol-gel procedures offer unique advantages such as the possibility of obtaining metastable materials, achieving superior purity and compositional homogeneity of the products at moderate temperatures with simple laboratory equipment [21]. Semiconductor photo-catalysts offer huge potential for elimination of toxic chemicals [22]. $\mathrm{ZnO}$, with bang gap $=3.37 \mathrm{eV}$, has become promising in the past few years because of its distinctive optoelectronic, catalytic, and photochemical properties [24, 25]. It crystallizes in a hexagonal wurtzite structure (zincite). The ZnO-mediated photocatalytic process has been successfully used to degrade organic pollutants [23,26]. The aim of this study was to synthesize zinc oxide of low dimension and investigate the morphological properties and surfactant 
Fig. 1 XRD pattern of $\mathrm{ZnO}$

nanoparticles: a as prepared,

b annealed sample

Fig. 2 SEM images of the a asprepared, b annealed $\mathrm{ZnO}$ nanoparticles at $500{ }^{\circ} \mathrm{C}$
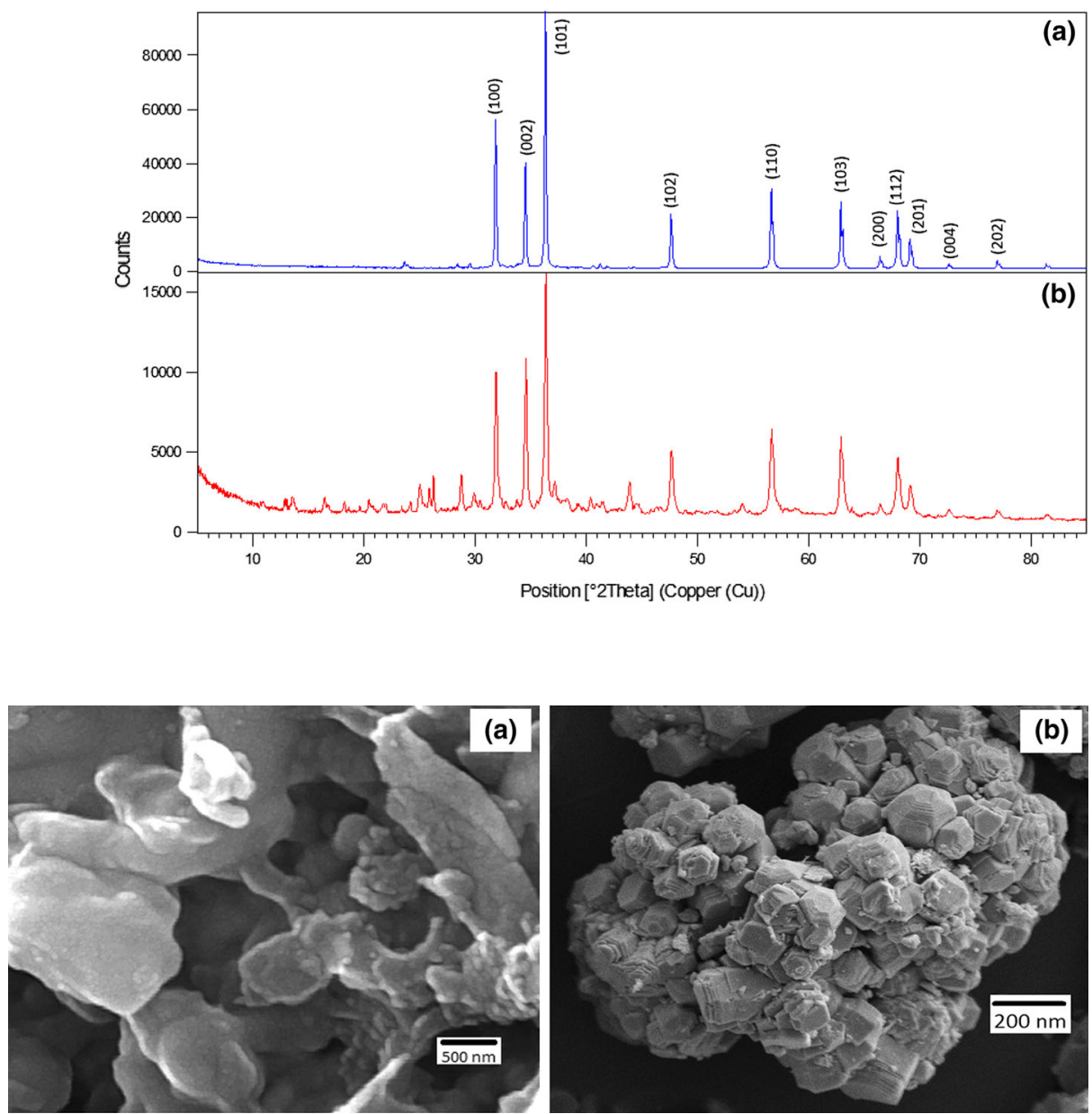

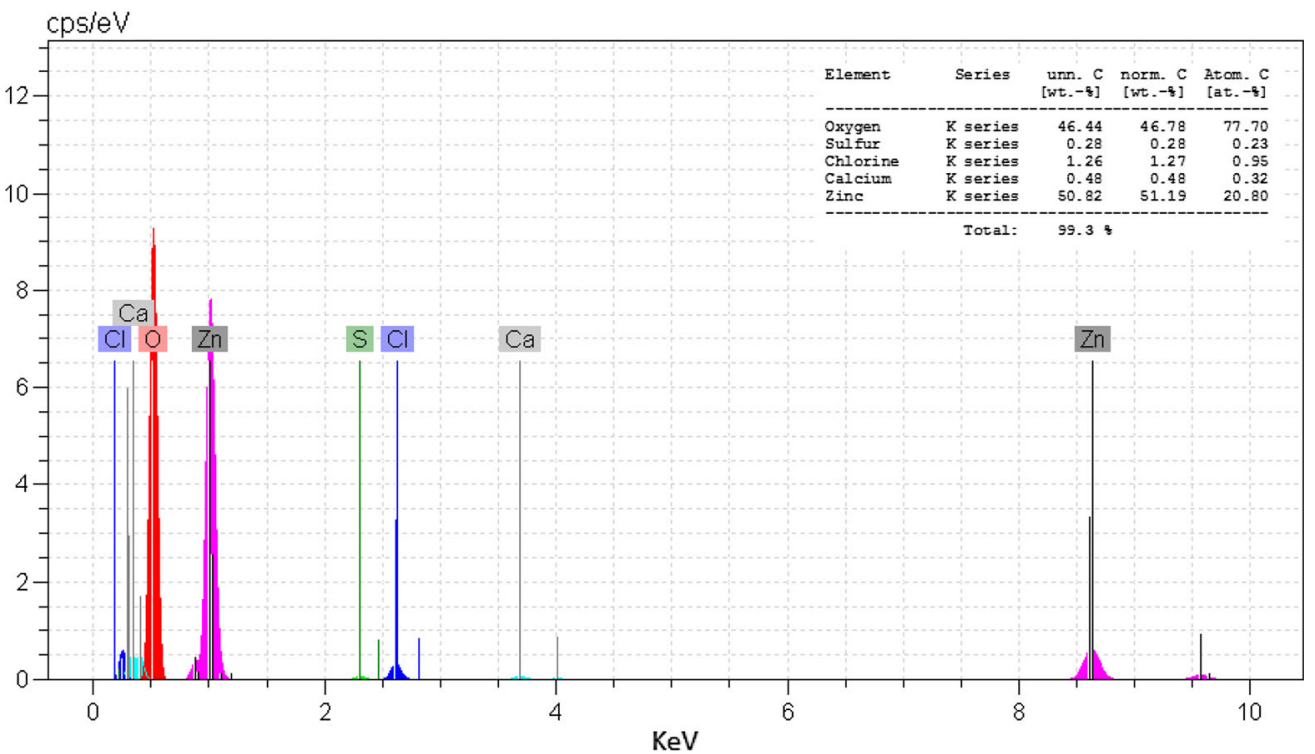

Fig. 3 EDS spectra of the as-synthesized $\mathrm{ZnO}$ prepared by wet synthesis 
effect on the particle size. This method has features, which are of considerable interest due to its low cost, easy preparation and industrial viability. The novelty of this method is that the samples were not purified and centrifuged in the fabrication stage because of oxidation. In many synthesis methods, the researchers purified samples to have uniform particles which oxidize $\mathrm{ZnO}$ nanoparticles by purification and centrifugation process [2, 8, 10-15]. Synthesis of $\mathrm{ZnO}$ nanoparticles by sol-gel technique is reported by $\mathrm{Zn}\left(\mathrm{NO}_{3}\right)_{2} \cdot 6 \mathrm{H}_{2} \mathrm{O}$ precursor and calcined at $500{ }^{\circ} \mathrm{C}$. The structural and morphological properties of $\mathrm{ZnO}$ have been studied by X-ray diffractometry (XRD), Fourier transform infrared spectroscopy (FTIR), ultraviolet-visible spectrophotometry (UV-Vis), spectroscopy, high-resolution transmission electron microscopy and scanning electron microscopy (SEM) analyses.

\section{Experimental details}

$\mathrm{ZnO}$ nanoparticles were synthesized by a new simple solgel approach in the following manner: In the first $30 \mathrm{~g}$, $\mathrm{ZnSO}_{4} \cdot 7 \mathrm{H}_{2} \mathrm{O}$ was dissolved in $150 \mathrm{~mL}$ deionized water and then $14 \mathrm{~mL}$ ethanol $(99.7 \%)$ was added to the solution. The mixed solution was stirred with a magnetic stirrer at $80{ }^{\circ} \mathrm{C}$ for $3 \mathrm{~h}$ to obtain the gel. The obtained gel was dried at $220^{\circ} \mathrm{C}$ for $1 \mathrm{~h}$ and then ground into fine particles. The temperature of the dried precursor powder was increased at the rate of $1{ }^{\circ} \mathrm{C} / \mathrm{min}$ to attain the required temperature and then the sample was allowed to stay at $500{ }^{\circ} \mathrm{C}$ for $3 \mathrm{~h}$ to obtain the $\mathrm{ZnO}$ nanoparticles.

The morphology of the as-synthesized and annealed $\mathrm{ZnO}$ nanoparticles was carried out. XRD was used to identify the crystalline phase and to estimate the crystalline size. The XRD patterns were recorded with $2 \theta$ in the range $4^{\circ}-85^{\circ}$ with $\mathrm{Cu}-\mathrm{K} \alpha$ : $\lambda=1.54 \AA$ model $X-\mathrm{PRt} \mathrm{PR}_{\theta} \mathrm{MPD}$. The morphology was characterized by an SEM model 3200 Ky-EM and transmission electron microscope (TEM) 900 ZEISSEM. All the measurements were carried out at room temperature. The optical properties of absorption were measured by UV-Vis model 300-sp and FTIR model 510-WQF.

\section{Results and discussion}

XRD at $40 \mathrm{kV}$ was used to identify crystalline phases and to estimate the crystalline sizes. Figure 1a shows the XRD morphology of the as-prepared $\mathrm{ZnO}$ nanoparticles and Fig. $1 \mathrm{~b}$ shows the sample annealed at $500{ }^{\circ} \mathrm{C}$ for $3 \mathrm{~h}$. In our case, all the diffraction peaks at angles $(2 \theta)$ of $31.36^{\circ}$, $34.03^{\circ}, 35.8^{\circ}, 47.16^{\circ}, 56.26^{\circ}, 62.54^{\circ}, 67.64^{\circ}, 68.79^{\circ}$, $69.45^{\circ}, 72.82^{\circ}$ and $77.33^{\circ}$ correspond to the reflection from
(100), (002), (101), (102), (110), (103), (200), (112), (201), (004) and (202) crystal planes of the hexagonal wurtzite zinc oxide structure. The mean size of the ordered $\mathrm{ZnO}$ nanoparticles has been estimated from full width at half maximum (FWHM) and Debye-Scherrer formula according to the following equation: [27]:

$D=\frac{0.89 \lambda}{B \cos \theta}$

where, 0.89 is the shape factor, $\lambda$ is the $\mathrm{X}$-ray wavelength, $B$ is the line broadening at half the maximum intensity (FWHM) in radians, and $\theta$ is the Bragg angle. The mean size of as-prepared $\mathrm{ZnO}$ nanoparticles was in the range 20-50 $\mathrm{nm}$ from this Debye-Scherrer equation.
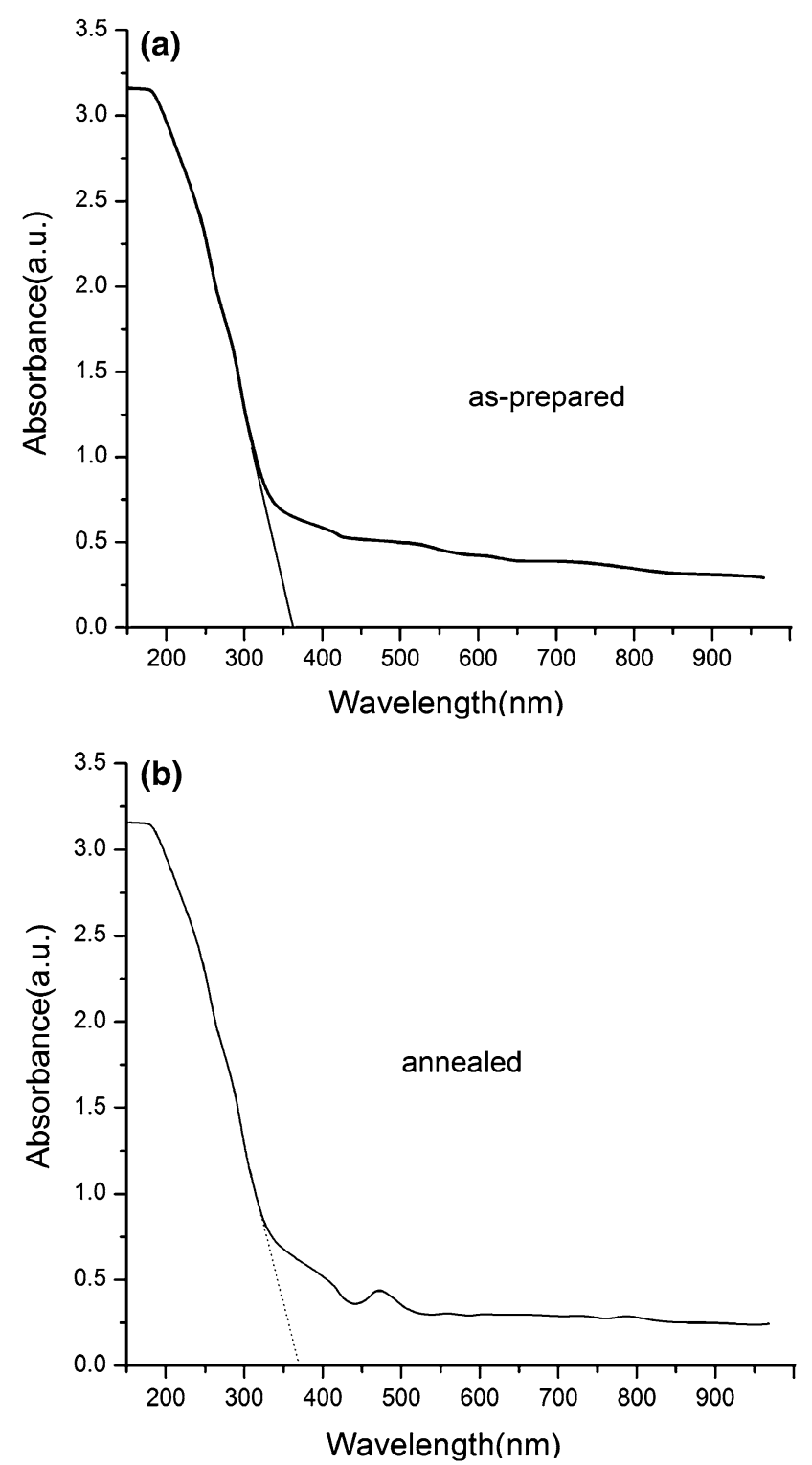

Fig. 4 UV-Vis absorption spectra of $\mathrm{ZnO}$ : a as-prepared, $\mathbf{b}$ annealed sample 
SEM analysis was used for the morphological study of $\mathrm{ZnO}$ nanoparticles. These analyses show that the multiple layered structure of obelisk-shaped $\mathrm{ZnO}$ nanoparticles are formed by increasing annealing temperature [28]. With increasing temperature the morphology of the particles changes to the pyramid shape and nanopowders were less agglomerated. Figure 2a shows the SEM image of the asprepared $\mathrm{ZnO}$ nanoparticles prepared by sol-gel method. In this figure, the particles were prepared with formation of clusters. Figure $2 \mathrm{~b}$ shows the SEM image of the $\mathrm{ZnO}$ nanoparticles annealed at $500{ }^{\circ} \mathrm{C}$ for $3 \mathrm{~h}$. It can be seen that the multiple layered of obelisk-shaped $\mathrm{ZnO}$ nanoparticles were less agglomerated.

Energy dispersive spectroscopy analysis of the $\mathrm{ZnO}$ samples is shown in Fig. 3. It confirms the existence of $\mathrm{Zn}$ and $\mathrm{O}$ with weight percent. EDS was used to analyze the chemical composition of a material under SEM. EDS measurement shows peaks of zinc and oxygen and indicates a few of impurities in prepared samples.

UV-visible absorption spectral study was done to understanding of the optical band gap of the material. Absorption in the near-ultraviolet region arises from electronic transitions associated within the sample. UV-Vis absorption spectra of as-prepared and annealed $\mathrm{ZnO}$ nanoparticles are shown in Fig. 4. As you can see from the pictures, the strong absorption band at a low wavelength near $370 \mathrm{~nm}$ corresponds to the bandgap energy of $3.35 \mathrm{eV}$ for the as-prepared sample, and the strong absorption band at the low wavelength near $379 \mathrm{~nm}$ corresponds to $3.27 \mathrm{eV}$ for the annealed nanoparticles. The size of particles changes with increasing temperature and the bandgap energy decreases with increasing annealing temperature.

Figure 5 shows the FTIR spectra of the $\mathrm{ZnO}$ powders, which were acquired in the range of $4000-400 \mathrm{~cm}^{-1}$. All of the spectra exhibit a strong absorption peak at $3508 \mathrm{~cm}^{-1}$ for stretching vibration of non-chemical bond association $\mathrm{OH}$ groups and at $1637 \mathrm{~cm}^{-1}$ for $\mathrm{H}-\mathrm{O}-\mathrm{H}$ bending vibrations. The peaks at $2390 \mathrm{~cm}^{-1}$ are attributed to the presence of carbon dioxide. The absorption peaks around $1392 \mathrm{~cm}^{-1}$ are assigned to the bending vibration of $\mathrm{C}-\mathrm{H}$ stretching. The peaks at $514-442 \mathrm{~cm}^{-1}$ are for $\mathrm{Zn}-\mathrm{O}$. The above results are in accordance with the XRD results.

The TEM analysis was carried out to confirm the actual size of the particles, their growth pattern and the distribution of the crystallites. Figure 6 shows the TEM image of spherical $\mathrm{ZnO}$ nanoparticles prepared by chemical sol-gel route. Figure 6 a shows the as-synthesized samples with an average diameter of $20 \mathrm{~nm}$. Figure $6 \mathrm{~b}$ indicates the annealed samples with an average diameter of $80 \mathrm{~nm}$. It can be seen that the size of nanoparticles increases with increasing annealing temperature. Because the increasing temperature remove the surfactants around the particles and the particles are closed to each other because of interactions.

\section{Conclusion}

A multiple-layered structure of obelisk-shaped $\mathrm{ZnO}$ nanoparticles was successfully synthesized by a new and simple sol-gel method using an ethanol solution of $\mathrm{Zn}\left(\mathrm{NO}_{3}\right)_{2} \cdot 6 \mathrm{H}_{2} \mathrm{O}$. The XRD results show that $\mathrm{ZnO}$ nanoparticles are hexagonal wurtzite in the size range 20-50 nm. From SEM images, it is clear that with increasing temperature, the morphology of the particles changes to the obelisk shape and the nanopowders were less agglomerated. The TEM image exhibits the as-synthesized $\mathrm{ZnO}$ nanoparticles prepared the by sol-gel route
Fig. 5 The Fourier transform infrared spectroscopy pattern of the zinc oxide nanoparticles

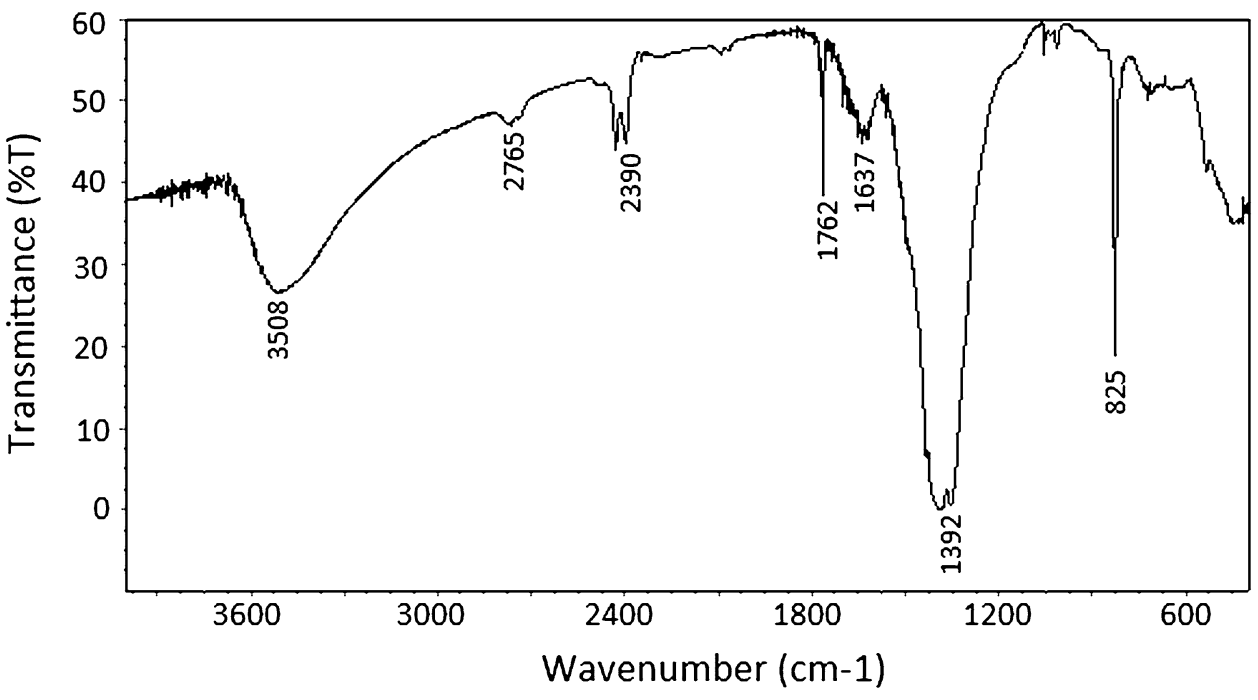



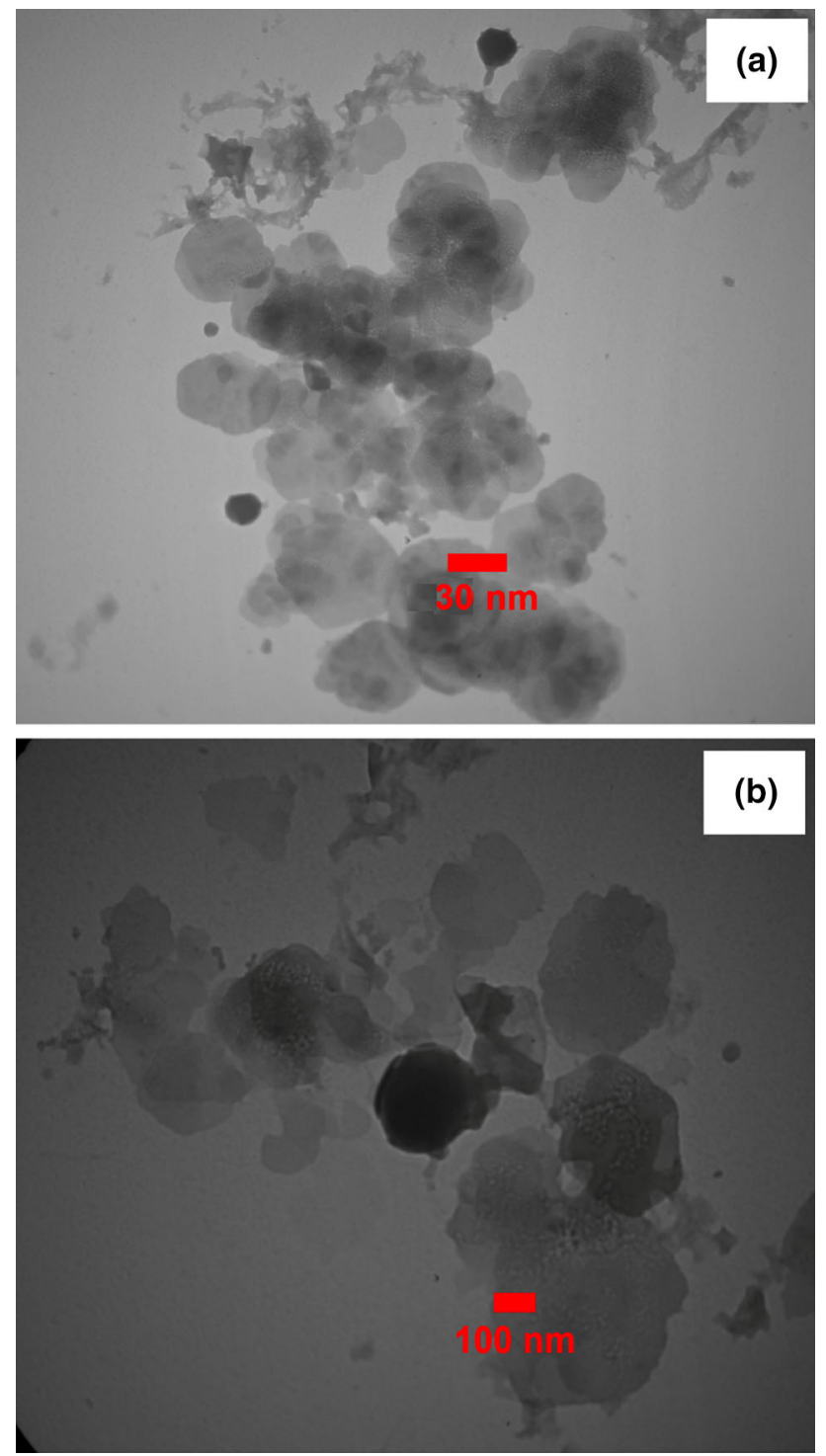

Fig. 6 TEM images of the $\mathrm{ZnO}$ nanoparticles: a as-prepared, b annealed samples

with average size of $20 \mathrm{~nm}$. The EDS measurements showed only peaks of zinc and oxygen and indicated the absence of impurities in the prepared $\mathrm{ZnO}$ samples. From the FTIR data, the presence of $\mathrm{Zn}-\mathrm{O}$ stretching mode of $\mathrm{ZnO}$ is shown. The zinc oxide nanoparticles show a strong UV-Vis absorption below $400 \mathrm{~nm}$ with a well-defined absorption peak at $370 \mathrm{~nm}$; the direct bandgap is found to be $3.35 \mathrm{eV}$.

Acknowledgments The authors are thankful for the financial support of Varamin Pishva Branch at Islamic Azad University for analysis and the discussions on the results.

Open Access This article is distributed under the terms of the Creative Commons Attribution 4.0 International License (http://crea tivecommons.org/licenses/by/4.0/), which permits unrestricted use, distribution, and reproduction in any medium, provided you give appropriate credit to the original author(s) and the source, provide a link to the Creative Commons license, and indicate if changes were made.

\section{References}

1. van Dijken, A., Meulenkamp, E.A., Vanmaekelbergh, D., Meijerink, A.: The luminescence of nanocrystalline $\mathrm{ZnO}$ particles: the mechanism of the ultraviolet and visible emission. J. Lumin. 87-89, 454-456 (2000)

2. Guo, L., Yang, S.H., Yang, C.L., Yu, P., Wang, J.N., Ge, W.K., Wong, G.K.L.: Synthesis and characterization of poly(vinylpyrrolidone)-modified zinc oxide nanoparticles. Chem. Mater. 12, 2268-2274 (2000)

3. Feng, Y., Zhou, Y.X., Liu, Y.Q., Zhang, G.B., Zhang, X.Y.: Photoluminescence spectra of nano-structured $\mathrm{ZnO}$ thin films. J. Lumin. 119-120, 233-236 (2006)

4. Hingorani, S., Pillai, V., Kumar, P., Multani, M.S., Shah, D.O.: Microemulsion mediated synthesis of zinc-oxide nanoparticles for varistor studies. Mater. Res. Bull. 28, 1303-1310 (1993)

5. Pillai, S.C., Kelly, J.M., McCormack, D.E., O’Brien, P., Ramesh, R.: The effect of processing conditions on varistors prepared from nanocrystalline ZnO. J. Mater. Chem. 13, 2586-2590 (2003)

6. Beek, W.J.E., Wienk, M.M., Janssen, R.A.J.: Efficient hybrid solar cells from zinc oxide nanoparticles and a conjugated polymer. Adv. Mater. 16, 1009-1013 (2004)

7. Epifani, M., Diaz, R., Arbiol, J., Comini, E., Sergent, N., Pagnier, T., Siciliano, P., Taglia, G., Morante, J.R.: Nanocrystalline metal oxides from the injection of metal oxide sols in coordinating solutions: synthesis, characterization, thermal stabilization, device processing, and gas-sensing properties. Adv. Funct. Mater. 16, 1488-1498 (2006)

8. Tang, H.X., Yan, M., Ma, X.F., Zhang, H., Wang, M., Yang, D.R.: Gas sensing behavior of polyvinylpyrrolidone-modified $\mathrm{ZnO}$ nanoparticles for trimethylamine. Sens. Actuators B 113, 324-328 (2006)

9. Trandafilović, L.V., Božanić, D.K., Dimitrijević-Branković, S., Luyt, A.S.: Fabrication and antibacterial properties of $\mathrm{ZnO}-\mathrm{al}-$ ginate nanocomposites. Carbohydr. Polym. Djoković V 88, 263-269 (2012)

10. Martins, N.C.T., Freire, C.R.S., Neto, C.P., Silvestre, A.J.D., Causio, J., Baldi, G.: Antibacterial paper based on composite coatings of nanofibrillated cellulose and $\mathrm{ZnO}$. Colloids Surf. A 417, 111-119 (2013)

11. Jalal, R., Goharshadi, E.K., Abareshi, M., Moosavi, M., Yousefi, A., Nancarrow, P.: ZnO nanofluids: green synthesis, characterization, and antibacterial activity. Mater. Chem. Phys. 121, 198-201 (2010)

12. Nair, M.G., Nirmala, M., Rekha, K., Anukaliani, A.: Structural, optical, photo catalytic and antibacterial activity of $\mathrm{ZnO}$ and $\mathrm{Co}$ doped $\mathrm{ZnO}$ nanoparticles. Mater. Lett. 65, 1797-1800 (2011)

13. Talebian, N., Nilforoushan, M.R., Zargar, E.B.: Enhanced antibacterial performance of hybrid semiconductor nanomaterials: $\mathrm{ZnO} / \mathrm{SnO}_{2}$ nanocomposite thin films. Appl. Surf. Sci. 258, 547-555 (2011)

14. Phan, D.T., Chung, G.S.: Effects of defects in Ga-doped $\mathrm{ZnO}$ nanorods formed by a hydrothermal method on CO sensing properties. Sens. Actuators B 187, 191-197 (2013)

15. Li, Q., Chen, Y., Luo, L., Wang, L., Yu, Y., Zhai, L.: Photoluminescence and wetting behavior of $\mathrm{ZnO}$ nanoparticles/nanorods array synthesized by thermal evaporation. J Alloys Compd. 560, 156-160 (2013) 
16. Azarang, M., Shuhaimi, A., Yousefi, R., Jahromi, S.P.: One-pot sol-gel synthesis of reduced graphene oxide uniformly decorated zinc oxide nanoparticles in starch environment for highly efficient photodegradation of methylene blue. RSC Adv. 5, 21888-21896 (2015)

17. Yousefi, R., Jamali-Sheini, F., Cheraghizade, M., KhosraviGandomani, S., Sáaedi, A., Huang, N.M., Basirun, W.J., Azarang, M.: Enhanced visible-light photocatalytic activity of strontiumdoped zinc oxide nanoparticles. Mater. Sci. Semicond. Process. 32, 152-159 (2015)

18. Zak, Khorsand: A., Majid, W.H.A., Darroudi, M., Yousefi, R.: Synthesis and characterization of $\mathrm{ZnO}$ nanoparticles prepared in gelatin media. Mater. Lett. 65, 70-73 (2011)

19. Ghandomani, S., Yousefi, R., Jamli-Sheini, F., Ming Huang, N.: Optical and electrical properties of p-type Ag-doped $\mathrm{ZnO}$ nanowires. Ceram. Int. 40, 7957-7963 (2014)

20. Azarang, M., Shuhaimi, A., Yousefi, R., Golsheikh, A.M., Sookhakian, M.: Synthesis and characterization of ZnO NPs/graphene oxide nanocomposite prepared in gelatin medium as highly efficient photo-degradation of MB. Ceram. Int. 40(2014), 10217-10221 (2014)

21. Yousefi, R., Khorsand-Zak, A., Jamali-Sheini, F.: Growth, X-ray peak broadening studies, and optical properties of Mg-doped $\mathrm{ZnO}$ nanoparticles. Mater. Sci. Semicond. Process. 16, 771-776 (2013)
22. Azarang, M., Shuhaimi, A., Yousefi, R., Sookhakian, M.: Effects of graphene oxide concentration on optical properties of $\mathrm{ZnO} /$ RGO nanocomposites and their application to photocurrent generation. J. Appl. Phys. 116, 084307-084312 (2014)

23. Height, M.J., Pratsinis, S.E., Mekasuwandumrong, O., Praserthdam, P.: Ag-ZnO catalysts for UV-photodegradation of methylene blue. Appl. Catal. B Environ. 63, 305-312 (2006)

24. Chen, C.C., Lu, C.S.: Mechanistic studies of the photocatalytic degradation of methyl green: an investigation of products of the decomposition processes. Environ. Sci. Technol. 41, 4389-4396 (2007)

25. Kuo, T.J., Lin, C.N., Kuo, C.L., Hung, M.H.: Growth of ultralong $\mathrm{ZnO}$ nanowires on silicon substrates by vapor transport and their use as recyclable photocatalysts. Chem. Mater. 19, 5143-5147 (2007)

26. Akyol, A.H., Yatmaz, C., Bayramoblu, M.: Photocatalytic decolorization of Remazol Red $\mathrm{R}$ in aqueous $\mathrm{ZnO}$ suspensions. Appl. Catal. B Environ. 54, 19-24 (2004)

27. Monshi, A., Foroughi, M.R., Monshi, M.R.: Modified Scherrer equation to estimate more accurately nano-crystallite size using XRD. World J. Nano Scie. Eng. 2, 154-160 (2012)

28. Baruah, S., Dutta, J.: Hydrothermal growth of $\mathrm{ZnO}$ nanostructures. Sci. Technol. Adv. Mater. 10, 013001-013019 (2009) 